\title{
Load-deformation Analysis of a Pile in Expansive Soil upon Infiltration
}

\author{
Yunlong Liu, Sai K. Vanapalli, Amina W. BA \\ Department of Civil Engineering, University of Ottawa \\ 161 Louis-Pasteur St., Ottawa, Canada \\ Liuyunlongzzu@hotmail.com; Vanapall@eng.uottawa.ca; Aba041@uottawa.ca
}

\begin{abstract}
Piles are widely used as foundations in regions with expansive soil deposits to safely carry loads from the superstructure to the soil without undergoing unacceptable deformations. These foundations are typically designed assuming that that the soil is in a state of saturated condition extending conventional soil mechanics principles. However, the soil surrounding the pile in expansive soils is typically in an unsaturated state. Due to this reason, the mechanical behaviour of the pile is significantly influenced by matric suction. In this paper, the pile load transfer model proposed by Zhang and Zhang (2012) is modified by taking account of the influence of matric suction on the pile-soil interface shear strength for estimating the load-deformation behaviour. In addition, an algorithm is developed for estimating the load-deformation analysis of a single pile in expansive soils, taking account of infiltration conditions. An example problem is presented for highlighting the influence of infiltration on the load settlement behavior of a single pile in Regina clay, which is a typical expansive soil from Canada.
\end{abstract}

Keywords: pile, expansive soil, load transfer, unsaturated soil

\section{Introduction}

Pile foundations are capable of carrying significantly large loads from the superstructure to the soil below safely without stability or deformation problems. These type of foundations are also widely used in expansive soils, which are typically found in an unsaturated state, with minor modifications in their design and construction procedures. The behaviour pile foundations in unsaturated expansive soils are significantly influenced by matric suction. However, it is typically ignored because the design of pile foundations is based on conventional soil mechanics assuming saturated soil conditions. Figure 1 illustrates the mechanical behavior of single pile in expansive soil before and after water or rainfall infiltration. Prior to infiltration, positive friction develops along the entire length of the pile. The load from the superstructure is carried along the length and at the end of the pile [as shown in Figure 1 (a)]. As water infiltrates into the active zone [as shown in Figure 1 (b)], three main changes that arise in the soil and pile behavior should be given due consideration for the rational design of pile foundations: (i) in vertical direction, volume expansion of soil causes ground heave; (ii) in the horizontal direction, restricted volume expansion contributes to the development of lateral swelling pressure, which should be taken into account; (iii) the pile-soil interface strength properties change due to variations in water content of the surrounding soil.

Most importantly, due to the influence of water infiltration in the active zone, uplift friction generates along the pile as a result of displacement between the pile and the adjacent soil (i.e. soil swells and moves upward relative to the pile). The magnitude of the uplift friction can be determined from the lateral earth pressure increase that arises from the contribution of lateral swelling pressure and the water content-dependent interface strength properties. In the stable zone (the depth below the active zone that is not influenced by water infiltration), negative friction arises when the pile moves upward relative to surrounding soil in the stable zone.

Currently, there is limited understanding of the comprehensive behavior of pile foundations in expansive soils [1]. For this reason, it is usually recommended to conduct in-situ tests [2] or perform numerical analysis to better understand the complexities associated with the piles behaviour in expansive soils [1][3][4][5]. However, in-situ pile testing is expensive and time-consuming while numerical analyses require complex constitutive relationships, which need many soil parameters. For engineering practice applications; a quick, simple and yet reliable and acceptable approach is required for better understanding the pile behavior upon infiltration. In this paper, the load transfer curve model proposed by [6] is 
modified taking account of the influence of matric suction on the pile-soil interface shear strength upon infiltration. Furthermore, the traditional load transfer method is modified to estimate the load settlement analysis of a single pile in expansive soil upon infiltration. An algorithm is written for performing the above analysis. In this paper, an example problem is presented to highlight the load-deformation behavior of a single pile placed in Regina clay, which is a typical example of expansive clay from Canada, due to water infiltration.

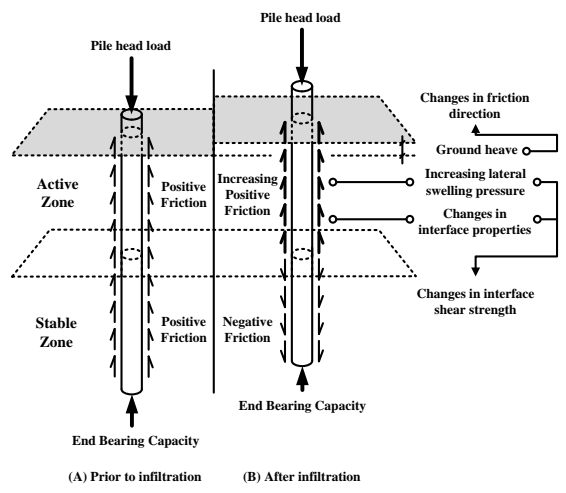

Fig. 1: Mechanical behavior changes of a pile placed in a typical expansive soil before and after infiltration.

\section{Background}

The load transfer method for the analysis of single pile settlement was originally proposed by [7]. The load-settlement curve can be reasonably estimated relating the interface shear strength properties to the pile settlement for pile head loads. The key information in this method is the curve relating the interface shear strength and the pile settlement. Such load transfer curves were developed originally by [8]. Since then, several other scholars have also contributed to better understand and estimate the load-settlement behavior of piles from load transfer curves. For example, [7] and [9] presented the load transfer curves suitable for different situations from laboratory or field tests, or a combination of both. The load transfer method has gained wider acceptance through decades of application studies [10].

In engineering practice, the shaft resistance degradation which has been investigated from field tests [11] [12] [13]; these studies suggest skin friction softening increases which contributes to pile settlement. However, very few approaches account for the skin friction softening. In order to address this limitation, [6] proposed a simplified approach for the nonlinear analysis of the load-displacement response of a single pile considering shaft resistance degradation and base resistance hardening.

The softening nonlinear model of unit skin friction is shown in Fig. 2 (a). Initially, the pile shaft friction increase nonlinearly with increasing pile head load. When the pile-soil relative displacement reaches $S_{s u}$, the unit shaft friction reaches a peak value $\tau_{s u}$. The unit shaft friction then decreases as the pile-soil relative displacement keeps increasing. The mathematical expression of the curve shown in Fig. 2 (a) is given as Eq. (1).

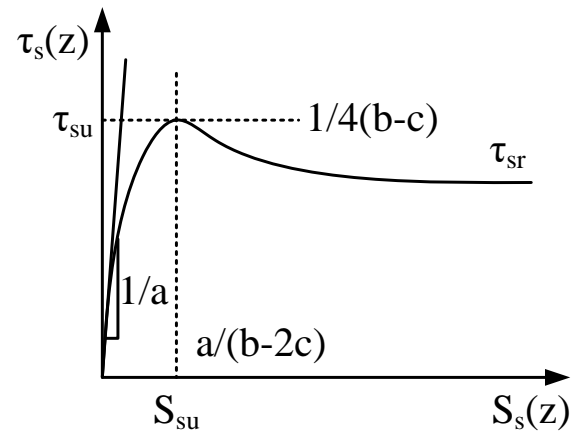

(a)

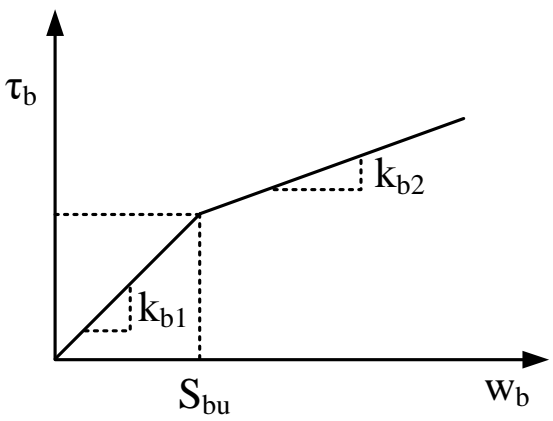

(b)

Fig. 2: (a) Relationship between the skin friction and relative shaft displacement at the pile-soil interface (Modified after [6]);

(b) Relationship between the base resistance and pile-end settlement. 


$$
\begin{gathered}
\tau_{s}(z)=\frac{S_{s}(z)\left[a+c S_{s}(z)\right]}{\left[a+b S_{s}(z)\right]^{2}} \\
\beta_{s}=\frac{\tau_{s r}}{\tau_{s u}}
\end{gathered}
$$

Where $\tau_{s}(z)$ is the shaft shear stress at a given depth, $z ; S_{s}(z)$ is the relative displacement along the pile-soil interface at a given depth, $z ; a=\frac{\beta_{s}-1+\sqrt{1-\beta_{s}}}{2 \beta_{s}} \frac{S_{s u}}{\tau_{s u}} ; b=\frac{1-\sqrt{1-\beta_{s}}}{2 \beta_{s}} \frac{1}{\tau_{s u}} ; c=\frac{2-\beta_{s}-2 \sqrt{1-\beta_{s}}}{4 \beta_{s}} \frac{1}{\tau_{s u}} ; S_{s u}$ is pile-soil relative displacement corresponding to peak interface shear strength; $\tau_{s u}$ is the peak interface shear strength; $\tau_{s r}$ is the residual interface shear strength; A series of field tests on bored piles under compression loading [11] [12] [13] demonstrated that the value of $\beta_{s}$ applied for bored piles have been found to be within the range of 0.83-0.97.

The bi-linear base load-displacement model is shown in Fig. 2 (b) and corresponding mathematical expression is given as Eq. (3).

$$
\tau_{b}=\left\{\begin{array}{l}
k_{b 1} w_{b} \quad w_{b}<S_{b u} \\
k_{b 1} S_{b u}+k_{b 2}\left(w_{b}-S_{b u}\right) \quad w_{b} \geq S_{b u}
\end{array}\right.
$$

Where $\tau_{b}$ and $w_{b}$ are the unit end resistance and the pile end displacement, respectively; $k_{b 1}$ and $k_{b 2}$ represent the compressive rigidity of the pile-tip soil in the first and second stages of the load-displacement curve, respectively; and $S_{b u}$ is the pile-end settlement related to the limiting end resistance in the first stage.

A model was proposed by [14] for the determination of $k_{b 1}$ as given in Eq. (4).

$$
k_{b 1}=\frac{4 G_{s b}}{\pi r_{0}\left(1-v_{b}\right)}
$$

Where $G_{s b}$ and $v_{b}$ are the shear modulus and Poisson's ratio of the soil below the pile base, respectively.

The value of $k_{b 2}$ can be approximately calculated using the Eq. (5) proposed by [15].

$$
k_{b 2}=\frac{\Delta P_{t}}{\Delta w_{t}-\left(\Delta P_{t} L / E_{p} A_{p}\right)}=\frac{k_{t}}{1-\left(k_{t} L / E_{p} A_{p}\right)}
$$

Where $\Delta P_{t}$ is the increased load on the pile head when the settlement at the pile base is larger than the limiting pile end settlement of the first stage of the $\tau_{b}-w_{b}$ curve; $\Delta w_{t}$ is the increased settlement at the pile head induced by $\Delta P_{t}$; $L$ is the pile length; $E_{p}$ is the pile elastic modulus; $A_{p}$ is the cross sectional area of the pile; and $k_{t}$ is the ratio of the load increment to the settlement increment at the pile head, $k_{t}=\Delta P_{t} / \Delta w_{t}$.

Based on the proposed two models (the softening nonlinear model of skin resistance and the bilinear base loaddisplacement model), using load transfer method proposed by [7], the load settlement response of a single pile can be obtained. The capacity of the proposed model is assessed by comparing the theoretical results with the experimental data from field measurement of pile for different types of soils (mud, sandy silt and clay). A satisfactory agreement has been achieved from these comparisons [6].

\section{Proposed method}


The load transfer model proposed by [6] has the ability to well simulate the relationship between the load and settlement of single pile under the application of an axial load. Furthermore, this relationship is has simple that is based on soil parameters determined from the conventional soil tests. This approach has been successfully applied for analyzing the load-deformation behavior of single piles in different kinds of soils (i.e. mud, sandy silt and clay). For this reason, in the present study, this model has been extended to describe the load-deformation behaviour of single pile in expansive soils with necessary modifications.

The stress state variables; namely, net normal stress and matric suction have a significant influence on the peak interface shear strength behavior of unsaturated soils. The peak interface shear strength of the unsaturated soil-structure interface can be modelled using Eq. (6) suggested by [16]. This equation was developed after conducting a series of interface direct shear test between the stainless steel plates and unsaturated soil for different values of matric suction.

$$
\tau_{s u}=c_{a}^{\prime}+\left(\sigma_{n f}-u_{a f}\right) \tan \delta^{\prime}+\left(u_{a f}-u_{w f}\right) \tan \delta^{\prime}\left(\frac{\theta-\theta_{r}}{\theta_{s}-\theta_{r}}\right)
$$

Where $c_{a}{ }^{\prime}$ is effective pile-soil interface cohesion; $\left(\sigma_{n f}-u_{a f}\right)$ is the net normal stress at failure, $\left(u_{a f}-u_{w f}\right)$ is the matric suction at failure, $\phi^{\prime}$ is the effective soil internal friction angle; $\theta$ is the current volumetric water content; $\theta_{r}$ is the residual volumetric water content; $\theta_{s}$ is the volumetric water content at a saturation of $100 \%$.

During the infiltration process, lateral swelling pressure develops in expansive soils when the volume expansion of soil surrounding the pile is restricted in horizontal direction. The generation of lateral swelling pressure can significantly increase the net normal stress that acts on the pile-soil interface. However, lateral swelling pressure is different from vertical swelling pressure for which standardized testing techniques and various estimation models are available (see the summary by [17] [18] [19]). Research studies regarding the measurement and estimation of LSP however are relatively limited [20]. In this study, the model proposed by [20] [Eq. (7)] is employed for the estimation of lateral earth pressure (considering the lateral swelling pressure) under surcharge from vertical swelling pressure.

$$
\left(\sigma_{n f}-u_{a f}\right)=\frac{\left(1-v-2 v^{2}\right) P_{S}}{1-v^{2}-\frac{P_{S}}{E_{a}}(1+v)\left(1-v-2 v^{2}\right)}+\frac{v}{1-v} \sigma_{S}
$$

Where $P_{s}$ is the vertical swelling pressure (constant volume condition); $E_{a}$ is the average elastic modulus with the variation suction range; $\sigma_{s}$ is the surcharge stress.

A semi-empirical equation [Eq. (8)] proposed by [21] is used in Eq. (7) for predicting the variation of vertical swelling pressure with respect to suction reduction. It should be noted that Eq. (8) is only suitable for the scenario of saturation soil condition. However, the water infiltration is a time dependent process and the degree of saturation increases with an increase in initial water content (i.e. reduction of soil suction), prior to reaching full saturation condition. The lateral earth pressure (considering the lateral swelling pressure) during the intermediate period during which the degree of saturation and suction changes can be calculated. For example from $\psi_{A}$ (initial state) to $\psi_{B}\left(\psi_{B}\right.$ is not zero), can be calculated as $\left(P_{S A}-\right.$ $\left.P_{S B}\right)$ using Eq. (8).

$$
P_{S}=P_{S 0}+\beta_{S} \cdot \psi \cdot\left(\frac{S_{r}}{100}\right)^{2}
$$

Where, $S_{r}$ is the degree of saturation, $P_{s 0}$ is the intercept on the $P_{s}$ axis at zero suction value $\left(P_{s 0}=55 \mathrm{kPa}\right.$ for compacted expansive soils), $\beta_{c}$ is fitting parameter, $\beta_{c}=\left(0.011 \mathrm{e}^{0.107 I_{p}}-7.872 \rho_{d, \max }+13.706\right) / 2, \rho_{d, \max }$ is the maximum density of the soil, , $I_{P}$ is the index of plasticity, $\psi$ is the soil suction.

A semi-empirical model [Eq. (9)] proposed by [22] has been used to predict the variation of average modulus of elasticity of unsaturated sandy soils with respect to matric suction using the SWCC. 


$$
E_{\text {unsat }}=E_{\text {sat }}\left[1+\alpha_{E} \frac{\left(u_{a}-u_{w}\right)}{\left(P_{a} / 101.3\right)} S^{\beta_{E}}\right]
$$

Where, $E_{\text {unsat }}$ is modulus of elasticity under unsaturated condition, $E_{s a t}$ is the saturated modulus of elasticity, $\alpha_{E}$ and $\beta_{E}$ are fitting parameters, and $P_{a}$ is atmospheric pressure (i.e. $101.3 \mathrm{kPa}$ ).

Eq. (9) proposed by [23] for fine-grained soils (i.e. $I_{P}>16 \%$ ) can be extended for unsaturated expansive soils to achieve a reasonable agreement using the fitting parameters $\alpha_{E}=0.05 \sim 0.15$ and $\beta_{E}=2$. This model can also be extended for estimating the average elastic modulus $E_{a}$ in Eq. (7). $E_{a}$ is defined as the average value of various $E_{\text {unsat }}$ values calculated using Eq. (9) over the range of matric suction variation.

Limited experimental results from interface direct shear tests [16] [24] suggest that the residual interface shear strength $\left(\tau_{s r}\right)$, is not significantly influenced by the matric suction. The reason for this behavior can be attributed to the shearing beyond the peak strength. During this stage of shearing (i.e. residual conditions), the air-water menisci are completely disrupted which results in a negligible strength contribution due to matric suction. However, the residual interface shear strength does increase with net normal stress at a given level of matric suction [21]. Extending this philosophy, the residual shear strength can be given as Eq. (10). However, in Eq. (10), both the residual effective cohesion $\left(c^{\prime}{ }_{a r}\right)$ and the residual interface friction angle $\left(\delta_{r}^{\prime}\right)$ should be determined from experimental studies. The relationship [Eq. (2)] between the peak interface shear strength and the residual interface shear strength can also be extended for pile-unsaturated soil interface.

$$
\tau_{s r}=c_{a r}^{\prime}+\left(\sigma_{n f}-u_{a f}\right) \tan \delta_{r}^{\prime}
$$

Where $c^{\prime}{ }_{a r}$ is the residual effective cohesion; $\delta_{r}^{\prime}$ is the residual interface friction angle.

The last parameter required is the pile soil relative displacement $\left(S_{u}\right)$ corresponding to the peak interface shear strength $\left(\tau_{s u}\right)$. As per earlier discussions, after the peak strength, due to the soil particle re-arrangement, the air-water menisci are completely disrupted. Due to this reason, the value of $\left(S_{u}\right)$ is not significantly influenced by the matric suction. This view point is supported by various experimental results [16] [24] [25]. Several factors influence the pile-soil interface behavior which include the soil type, pile type, consolidation condition of the soil, construction method and environmental factors. All these factors may pose some influence on the value of $S_{s u}$ and contribute to the peak unit shaft friction and hence may be difficult to assess. Considering these difficulties, it is suggested that $S_{s u}$ to be determined experimentally or from backanalysis of the field load test results. From a series of field tests [11] [12] [13], [6] summarized that the value of $S_{s u}$ varies within a range from 5 to $25 \mathrm{~mm}$ for bored piles with diameter from $0.7-1.1 \mathrm{~m}$ in different kind soils (e.g., mud, clay, sandy silt, silty clay).

The load transfer methods proposed by Coyle and Reese (1966) are widely utilized to predict the load-settlement behavior of single piles subjected to axial load because they suggest relatively simple analytical procedure and can be applied to any complex composition of soil layers with a nonlinear stress-strain relationship, nonhomogeneous medium, and any variation in the section along a pile (Poulos and Davis 1980). The load settlement behavior of a single pile in unsaturated expansive soils upon infiltration can be analyzed by modifying the traditional load transfer method, extending the following key assumptions: (i). The length pile is divided into a number of segments; (ii). Assuming a small tip movement, $\rho_{t}$; the point resistance, $P_{t}$, caused by this movement is calculated using Eq. (3). In this study the likely situation that the pile tip has detached with the soil is not considered. (iii). A movement, $\rho_{3}$, at mid-height of the bottom segment is assumed (for the first trial, it is suggested that $\rho_{3}=\rho_{t}$ ). (iv). The suction profile keeps changing during the infiltration process. For a certain suction profile at a certain time, a relevant load transfer curve at a certain depth can be estimated using the proposed method in this study. (v). From the estimated load-transfer curve, the shear strength of the soil at the depth of the segment corresponding to movement $\rho_{3}$ can be obtained as $\tau_{3}$. It should be noted that in the active zone, the pile-soil relative displacement should consider the possible ground heave for rigorous analysis. The ground heave at different depth can be simply estimated using Eq. (11) proposed by (23). (vi). The load $Q_{3}$ on the top of segment can then be calculated as Eq. (12); (vii). The elastic deformation at the midpoint of the pile segment (assuming a linear variation of load in the segment) is calculated using Eq. (13); (viii). The new movement at the mid-point of the segment is considered as Eq. (14); (ix). The calculated $\rho_{3}^{\prime}$ is compared with the estimated value of $\rho_{3}$ from step (4); (x). If the computed 
movement $\rho_{3}^{\prime}$ does not agree with $\rho_{3}$ within a specified tolerance, step (2) to step (10) are repeated and a new mid-point movement is calculated; (xi). The next segment up is considered after achieving convergence. This iteration procedure continues until the value of pile head load $\left(Q_{0}\right)$ and pile head displacement $\left(\rho_{0}\right)$ are obtained; (xii). A load-deformation curve can be achieved with respect to different base settlement for a certain suction profile, following the procedure from step (i) to step (xii). The pile head load-settlement curve can be obtained by accumulating the pile load and settlement at the top of each segment.

$$
\Delta h=h\left[\frac{(1+v)(1-2 v)}{E_{a}(1-v)}\right] \Delta\left(u_{a}-u_{w}\right)
$$

Where $\Delta h$ is heave of soil; $h$ is thickness of the calculated soil layer; $\Delta\left(u_{a}-u_{w}\right)$ is the suction reduction.

$$
Q_{3}=P_{t}+\tau_{3} L_{3} P_{3}
$$

Where L3 is length of segment 3; P3 is average perimeter of segment 3.

$$
\Delta^{\prime} \rho_{3}=\left(\frac{Q_{m}+P_{t}}{2}\right)\left(\frac{L_{3}}{2 A_{3} E_{p}}\right)
$$

Where $Q_{m}=\frac{Q_{3}+P_{t}}{2} ; A_{3}$ is area of segment $3 ; E_{p}$ is elastic modulus of the pile.

$$
\rho_{3}^{\prime}=\rho_{t}+\Delta \rho_{3}^{\prime}
$$

\section{Example problem}

In order to better illustrate the algorithm proposed in this paper, an example problem is presented in this section. It is assumed that a single pile is constructed in Regina clay, a typical expansive soil from Canada. The load-deformation response of the pile upon infiltration is analysed using the proposed method. The geometry and soil properties are derived from a case study presented by [26]. Fig. 5 presents the SWCC given by [26] which was estimated using equation given by [27]. Properties of Regina clay are summarized from Vu and Fredlund (2004) are the following: Liquid limit (LL)=77\%; Plastic limit $(\mathrm{PL})=33 \%$; Specific gravity $(G)=2.82$; Unit weight $(\gamma)=18.8 \mathrm{kN} / \mathrm{m}^{3}$; Initial void ratio $\left(e_{0}\right)=0.962 ;$ Swelling index $\left(C_{s}\right)=0.09$; Saturated coefficient of permeability $\left(k_{s a t}\right)=6.8 \times 10^{-5} \mathrm{~m} /$ day; Saturated volumetric water content $\left(\theta_{s}\right)=$ 0.493; Natural water content $=0.29$. However, shear strength properties are not available in this testing program. Instead, shear strength properties used in this example problem are derived from the tests conducted by [28] on Regina clay. In this example problem, the interface friction angle with respect to net normal stress $\left(\delta^{\prime}\right)$, the interface friction angle with respect to matric suction $\left(\delta^{b}\right)$ and interface cohesion $\left(c_{a}\right)$ is $60 \%$ of the internal friction angle of soil with respect to net normal stress $\left(\phi^{\prime}\right)$, soil internal friction angle with respect to matric suction $\left(\phi^{b}\right)$ and soil cohesion $\left(c^{\prime}\right)$, respectively. These assumptions with respect to interface properties are based on the conclusions presented by [16]. The assumed shear strength properties are summarized as following: Effective internal friction angle of soil with respect to net normal stress $\left(\phi^{\prime}\right)=27.9^{\circ}$; Internal friction angle of soil with respect to matric suction $\left(\phi^{b}\right)=19.8^{\circ}$; Effective interface friction angle with respect to net normal stress $\left(\delta^{\prime}\right)=16.7^{\circ}$; Interface friction angle with respect to matric suction $\left(\delta^{b}\right)=11.9^{\circ}$; Effective soil cohesion $\left(c^{\prime}\right)=16.3 \mathrm{kPa}$; Effective interface cohesion $\left(c_{a}\right)=9.8 \mathrm{kPa}$.

Fig. 3 shows the geometry of the example problem. A pile ( $4 \mathrm{~m}$ in length and $0.5 \mathrm{~m}$ in diameter) is assumed to be installed in Regina clay. In the calculation, the pile is divided into eight segments: four of these segments are located in the active zone and the remainder four segments are in the stable zone. The elastic modulus of the pile is set as 30GPa (reinforced concrete pile), the pile soil residual shear strength is set as 60 percent of the peak shear strength and the pile soil relative displacement is set as $(10 \mathrm{~mm})$ which is $1 / 50$ of the pile diameter. The saturated elastic modulus of Regina clay 
is set as $5 \mathrm{MPa}$ and Poisson's ratio is set as 0.3 . The initial suction profile given by [26], which is $-888 \mathrm{kPa}$ at the ground surface and $-12 \mathrm{kPa}$ at the bottom of the active zone is used. One year after construction, the hot water pipe leakage was detected and the soil in the active zone gradually achieved saturation conditions with respect to time. Three different states were considered during the saturation process for analysis in this example problem. State 1 represents the initial suction profile before water infiltration, State $\mathbf{2}$ signifies the suction profile during the mid-time and State $\mathbf{3}$ marks the final steady state.

Fig. 4 shows the relationship between the pile head load and settlement. From Fig. 4, pile shows different behavior with suction decreases under different magnitudes of pile head load. When the pile head load is lower than approximately $170 \mathrm{kN}$, the pile movement tends to be upwards upon infiltration. However, when the pile head load is higher than this value, the pile experiences downward movement upon infiltration. The reason for these behaviors can be explained as below; for pile under a head load lower than $170 \mathrm{kN}$, prior to infiltration the pile shaft friction is only partially mobilized (which is far less than the peak shear strength). Upon infiltration, the shaft friction increases with increasing pile soil relative displacement in the active zone. Due to this reason, the total uplift force outweighs the downward dragging force contributing to the upward movement of pile. However, when the pile is under a head load higher than $170 \mathrm{kN}$, prior to infiltration, the shaft friction contribution along the pile arises from fully mobilised peak shear strength parameters. Upon infiltration, increasing pile soil relative displacement causes an interface shear strength decrease from peak to the residual shear strength. The pile experiences settlement due to decrease in the shaft resistance. The pile head load of $170 \mathrm{kN}$ can be considered to be a value which differentiates between the light and heavy structure based on the pile-soil movement upon infiltration.

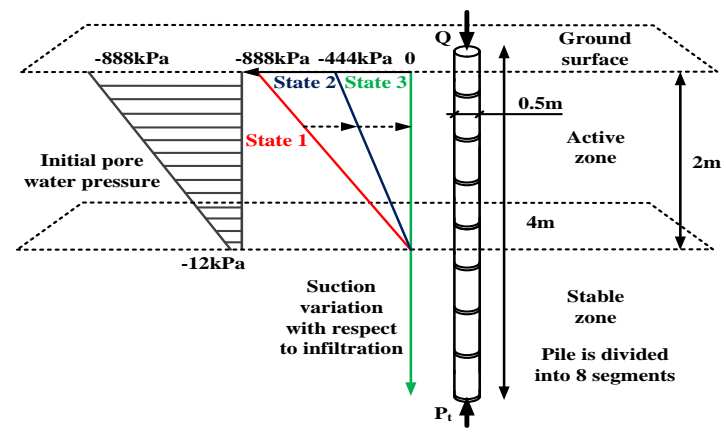

Fig. 3: Geometry of the example problem.

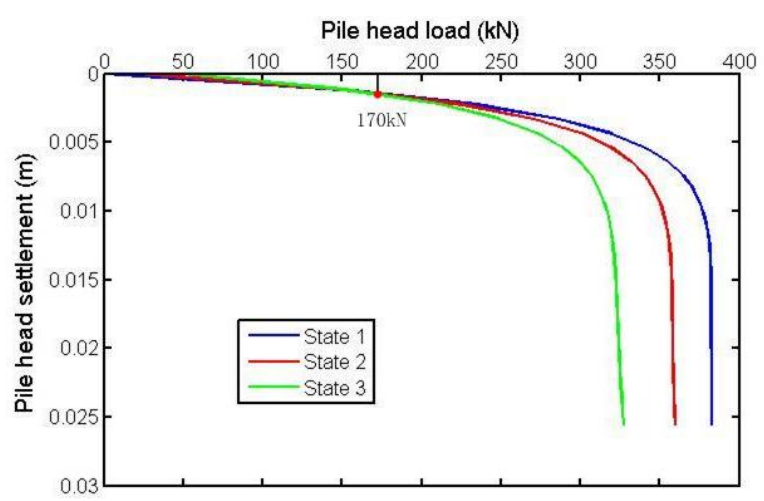

Fig. 4: Pile head load settlement relationship.

\section{Conclusions}

The suction profile variation associated with infiltration has a significant influence on the mechanical behavior of pier or pile foundations in unsaturated expansive soil deposits. In this paper, an algorithm is proposed based on the traditional load transfer method presented by [11] to study the pile load-deformation behavior of a single pile in unsaturated expansive soil due to variation in suction profile associated with water infiltration. An example problem is presented in this paper assuming that a single pile is constructed in Regina clay, which is typical expansive soil from Canada. The results of the 
study indicate that for a lightly loaded pile (e.g., for light structures), the shaft friction is only partially mobilized. For such a scenario, typically there will be an upward pile movement. However, for heavy structures, peak shear strength fully mobilizes along the pile shaft offering resistance to pile soil relative displacement (i.e. ground heave). Once the peak shear strength value reduces to residual value, shaft friction contribution decreases rapidly. As a consequence, the pile will be subjected to a settlement into the ground. The algorithm proposed in this paper is promising for reasonable estimation of the load-deformation behavior of pile in unsaturated expansive soils. However, the proposed model has to be validated against case studies results in the future for understanding the strengths and limitations of the proposed algorithm.

\section{Acknowledgements}

The authors acknowledge the research funding and financial support from the Natural Sciences and Engineering

Research Council of Canada (NSERC) and China Scholarship Council - University of Ottawa Joint Scholarship.

\section{References}

[1] J. D. Nelson, K. C. Chao, D. D. Overton, and E. J. Nelson, Foundation Engineering for Expansive Soils, John Wiley \& Sons, Hoboken, New Jersey, 2015.

[2] Ministry of Housing and Urban-Rural Development of the People's Republic of China (MOHURD), Technical code for building in expansive regions, China Architecture \& Building Press, Beijing, 2013.

[3] R. D. Ellison, E. Dappolnia, and G. R. Thiers, "Load deformation mechanism for bored piles," J Soil Mech Fdns, ASCE., vol. 97, pp. 661-72, 1971.

[4] J. L. Justo, J. E. Rodriguez, A. Delgado, and A. Jaramillo, "A finite element method to design and calculate pier foundations in expansive soils," in Proceedings of Fifth International Conference on Expansive Soils, Adelaide, Australia, 1984, pp. 119-123.

[5] F. H. Chen, Foundations on expansive soils, Elsevier, New York, 1988.

[6] Q. Q. Zhang, and Z. M. Zhang, "A simplified nonlinear approach for single pile settlement analysis," Canadian Geotechnical Journal, vol. 49, pp. 1256-1266, 2012.

[7] H. M. Coyle, and L. C. Reese, "Load transfer for axially loaded piles in clay," J.S.M.F.D, ASCE, vol. 92(SM2), pp. 126, 1966.

[8] H. B. Seed, and L. C. Reese, "The action of soft clay along friction piles," Trans, ASCE, vol. 122, pp. 731-754, 1957.

[9] H. M. Coyle, and I. H. Sulaiman, "Skin friction for steel pile in sand," J.S.M.F.D, ASCE, vol. 93(SM6), pp. 261-278, 1967.

[10] H. G. Poulos, E. H. Davis, Pile foundation analysis and design (No. Monograph), 1980.

[11] Q. Q. Zhang, Z. M. Zhang, F. Yu, and J. W. Liu, "Field performance of long bored piles within piled rafts," in Proceedings of the institution of Civil engineers: Geotechnical Engineering, vol. 163, no. 6, pp. 293-305, 2010.

[12] Z. M. Zhang, Q. Q. Zhang, and F. Yu, "A destructive field study on the behavior of pile under tension and compression," Journal of Zhejiang University-Science A, vol. 12, no. 4, pp. 291-300, 2011.

[13] Z. M. Zhang, Q. Q. Zhang, G. X. Zhang, and M. F. Shi, "Large tonnage tests on super-long piles in soft soil area," Chinese Journal of Geotechnical Engineering, vol. 33, no. 4, pp. 535-543, 2011. (In Chinese)

[14] M. F. Randolph, and C. P. Wroth, "Analysis of deformation of vertically loaded piles," Journal of the Geotechnical Engineering Division, ASCE, vol. 104, no. 12, pp. 1465-1488, 1978.

[15] Q. Q. Zhang, Z. M. Zhang, and J. Y. He, "A simplified approach for settlement analysis of single pile and pile groups considering interaction between identical piles in multilayered soils," Computers and Geotechnics, vol. 37, no. 7-8, pp. 969-976, 2010.

[16] T. B. Hamid, and G. A. Miller, "Shear strength of unsaturated soil interfaces," Canadian Geotechnical Journal, vol. 46, no. 5, pp. 595-606, 2009.

[17] J. D. Nelson, and D. J. Miller, Expansive soils-problems and practice in foundation and pavement engineering. Willy, New York, 1992.

[18] B. H. Rao, K. Venkataramana, and D. N. Singh, "Studies on the determination of swelling properties of soils from suction measurements," Canadian Geotechnical Journal, vol. 48, no. 3, pp. 375-387, 2011. 
[19] Ö. Çimen, S. N. Keskin, and H. Yıldırım, "Prediction of swelling potential and pressure in compacted clay," Arabian Journal for Science and Engineering, vol. 37, no. 6, pp. 1535-1546, 2012.

[20] Y. Liu, and S. K. Vanapalli, "Influence of lateral swelling pressure on the geotechnical infrastructure in expansive soils," Journal of Geotechnical and Geoenvironmental Engineering (accepted), 2016.

[21] H. Y. Tu, and S. K. Vanapalli, "Prediction of the variation of swelling pressure and 1-D heave of expansive soils with respect to suction using the soil water retention curve as a tool," Canadian Technique Journal, vol. 53, no. 8, pp. 1213-1234, 2016.

[22] W. T.Oh, S. K. Vanapalli, and A. J. Puppala, "Semi-empirical model for the prediction of modulus of elasticity for unsaturated soils," Canadian Geotechnical Journal, vol. 46, no. 8, pp. 903-914, 2009.

[23] H. H. Adem, and S. K. Vanapalli, "Elasticity moduli of expansive soils from dimensional analysis," Geotechnical Research, 60-72, vol. 1, no. 2, pp. 60-72, 2014.

[24] M. A. Hossain, J. H. Yin, "Unsaturated soil-cement interface behaviour in direct shear tests," Australian Geomechanics Journal, vol. 48, no. 3, p. 141-154, 2013.

[25] Z. H. Fan, "Research on swelling-shrinkage characteristic and pile-soil interaction of expansive soil foundation," Ph.D. thesis, Central South University, Changsha, China, 2007. (In Chinese)

[26] H. Q. Vu, and D. G. Fredlund, "The prediction of one, two- and three-dimensional heave in expansive soils," Canadian Geotechnical Journal, vol. 4, pp. 1-25, 2004.

[27] D. G. Fredlund, and A. Xing, "Equations for soil-water characteristic curve," Canadian Geotechnical Journal, vol. 31, no. 3, pp. 521-532, 1994.

[28] R. H. Chowdhury, and A. Shahid, "Unsaturated shear strength properties of a compacted expansive soil from Regina, Canada," Innovative Infrastructure Solutions, vol. 1, no. 1, pp. 47, 2016. 